\title{
On Statehood
}

\section{Failed Statehood in China}

Tang did not develop his ideas about a modern state out of a purely theoretical interest, but in the context of his diagnosis that China's current political impasse, which he saw culminating in the communist victory on the Mainland in 1949, mostly consists of failures in state-building. ${ }^{1} \mathrm{He}$ was convinced that these failures were mainly due to the dubious heritage bequeathed to the republic by imperial China, a heritage that entailed the notion of a spiritual ecumene (tianxia 天下) ${ }^{2}$ with an empire at the center of political power. In referring to the beginnings of imperial China, Tang asserted that with the unification of the ecumene during the Qin and the Han Dynasties, the concept of "statelet" (guo 國) became blurred and eventually disappeared altogether. Henceforth, the "clan system" (zongfa zhidu 宗法制度) was firmly established, while it was up to the literati-officials to consider themselves responsible for the fate of the ecumene. The concepts of clan/family (jiating 家庭) and ecumene thus won out. ${ }^{3}$ This constellation is said to have remained for the most part unchanged in the course of Chinese history. As a consequence, the imagery of an ecumenical empire produced a type of "universalism" (shijiezhuyi 世界主義) that transgressed the particularistic notion of strengthening the dynastic state according to the legalist "principle of wealth and power" ( fuqiangzhuyi 富強 主義). Tang deemed this to be an unfortunate development, because it was the particularistic concept of the dynastic state that might have been conducive to the intellectual evolution of a modern Chinese nation-state (minzu guojia 民族國家). Instead, Chinese concepts of state became engulfed by the universalistic notion of an ecumenical empire which blocked the coinage of a

1 Tang, Zhonghua renwen yu dangjin shijie bubian, Vol. 10, p. 165 .

2 The notion of "ecumene" (tianxia 天下) as applied to pre-imperial periods refers to the royal domain of the Zhou kings; with the unification of the empire and the ensuing dissolution of a royal domain, "tianxia" took on other meanings, including that of a global community consisting of civilized and not-yet civilized peoples; see also Weber-Schafer, Oikumene und Imperium, p. 9. Tang at times denoted by the term "tianxia" simply the "world" in a broad historical sense; see for example Tang, Zhonghua renwen yu dangjin shijie, Vol. 2, p. 409.

3 Tang, Zhonghua renwen yu dangjin shijie bubian, Vol. 10, p. 154. 
modern concept of state. According to Tang, this amounted to the "deepest inner contradiction" of Chinese state-building up to the present time. ${ }^{4}$

Tang deplored the fact that the legalist notion of a powerful dynastic state had been downplayed in the historical evolution of Chinese political thought. He actually maintained that only legalism might have nurtured Western-type concepts of state. He further contended that as a result of the domination of ecumenical universalism, the Chinese developed a spirit of "self-oblivion" (wang wo 忘我), which left them incapable of taking hostile attitudes toward the outside world. ${ }^{5}$ Tang's analysis of China's failure to deploy a nation-state concept is without a doubt open to historical criticism. Still, his analysis is remarkable due to his refusal to portray Legalism as the historical culprit, as Confucian mainstream narratives would have it. What is more, given Tang's assumption that a strong nation-state was indispensable for guiding the process of modernization, this diagnosis refers back to a depiction of China's thorny path to modernity. The bleak conclusion is that even though there were notions of empire and nation in traditional China, it took the historical events of the Qing Empire's encounter with Western and Japanese imperialism to pave the way for a concept of nation-state. Tang suggests that, as late as the 19th century and under "the impression of an invasion from the West," China finally became aware of "modern industrial organization" and modern nation-states. During the confrontation with the "dynamic power of "hard, crystalline states'," the traditional "consciousness of an ecumenical empire" (tianxia yishi 天下意識) began to crumble. ${ }^{6}$ Since then, there was the transformation from the "heavenly state" (tian guo 天國) of the Taiping movement to the "earthly state" (di guo 地國) of communist China, while the breakthrough to a "human state" (ren guo 人國) had not yet been achieved. ${ }^{7}$

What Tang meant by the incomplete breakthrough of the "human state" can be seen from his highly critical judgment of the ideas of state that were popular with Chinese elites at the end of the Qing Dynasty and the beginning of the Republican period. Tang believed that, whereas the traditional clan system finally withered away during the period of China's encounter with the West, the notion of an ecumenical empire lingered on, preventing the idea of a nation-state from gaining wide acceptance. He cited Tan Sitong, Kang Youwei, and Zhang Taiyan as thinkers who failed to devise a modern concept

\footnotetext{
4 Tang, Renwen jingshen zhi chongjian, p. 265.

5 Ibid., p. 266.

6 Tang, Zhongguo renwen jingshen zhi fazhan, p. 225; see also pp. 193-194.

7 Tang, Renwen jingshen zhi chongjian, p. 263.
} 
of the nation-state, even though they rejected the traditional notions of family and clan. To be sure, they strove for the preservation of the "land" and the "race," but they still clung to the notion of the ecumenical empire and hence neglected the nation-state. ${ }^{8}$ This outlook, according to Tang, was in line with traditional Chinese political thought, which envisions a world unified without states. $^{9}$

In his critique of Chinese thinkers who failed to establish a concept of state, Tang also included Liang Qichao and Sun Yat-sen. He elaborated that although Liang had been aware of the importance of the state and Sun of the importance of the nation, they, too, like Kang Youwei and Zhang Taiyan, upheld a vision of universal commonality, while neglecting the idea of elevating the state to the highest position. ${ }^{10}$ Tang's criticism of Liang and Sun in particular seems unjustified and can only be understood in the context of his attempt to develop a new concept of state which should reconcile - in a Hegelian wayethics, the moral consciousness of the individual, and a constitutional state based on the rule of law (see below). Significantly, he contradicted Sun Yat-sen, who assumed in The Three Principles of the People that while a nation like the Chinese developed out of "natural," non-violent resources, a state is predominantly the product of coercive means. ${ }^{11}$

The New Culture Movement which emerged during the second half of the 1910 allegedly also failed to develop an adequate concept of state, although it succeeded in destroying the traditional "consciousness of the family" (jiating $y$ ishi 家庭意識) in Chinese society. ${ }^{12}$ Tang assumed that the reasons why proponents of the New Culture Movement were not aware of the need to establish a strong and unified nation-state must be sought in their preoccupation with criticizing Chinese culture and history. ${ }^{13}$ This rebuke, however, was not meant

Tang, Zhonghua renwen yu dangjin shijie bubian, Vol. 10, p. 155. Tang lists in this context Kang Youwei's The Book of Great Uniformity, Tan Sitong's tract On Humanity (Renxue 仁學, written in 1896/7) and Zhang Taiyan's essay “On the Five Negations” (Wu wu lun 五無論, published in the Minbao 民報 in 1907).

9 Tang, Zhonghua renwen yu dangjin shijie bubian, Vol. 10, p. 160.

10 Tang, Renwen jingshen zhi chongjian, p. 265.

11 Tang, Zhonghua renwen yu dangjin shijie bubian, Vol. 10, pp. 155-156; see also p. 161. Tang was also convinced that it was detrimental to the establishment of a modern state with a democratic, constitutional government to focus, in the way Sun did, solely on nationalism and national consciousness, the so-called "people's rights" (min quan 民權) and “people's livelihood” (min sheng 民生); see ibid., pp. 159-161.

12 Ibid., pp. 155-156.

13 Tang, Renwen jingshen zhi chongjian, p. 266. 
as a complete rejection of the movement. Tang rather took issue with the movement's refusal to merge its call for political reform and national reconstruction with a sound reinterpretation of China's intellectual and historical traditions. He felt that by detaching itself from these traditions in a sweeping manner, the movement not only failed to gain broader acceptance of its political ideas, but it also missed an opportunity to critically reflect on its own attempt to absorb Western thought, traditions, and institutions. ${ }^{14}$

With respect to Chinese socialism, Tang astutely observed that the notion of an ecumenical empire was still present, albeit in a different form..$^{15}$ For one, the aforementioned attitude of self-oblivion, together with the inability to perceive the hostility of the outside world, led the CCP to forget, all too willingly, the crimes committed by the Soviet Union when invading China's northeast. In the same spirit, he continued, countless Chinese youth were convinced that it would be possible to create a new world order. The traditional notion of the "ecumene as one family" (tianxia yi jia 天下一家) would be realized by the "brotherly friendship" of the Soviet Union and China. ${ }^{16}$ Tang hinted in this context at the conclusion that the Marxists' negative view of the state as an instrument for repression readily accommodated the traditional, universalistic notion of a global ecumene. ${ }^{17}$

In spite of his elevation of the "consciousness of the state" to a position of eminent historical importance, Tang did not subscribe to the exaltation of the state in the circles of the Chinese Youth Party and the GMD's right wing. He strongly criticized the "stateism" (guojiazhuyi 國家主義) of the Youth Party with its organic concept of the state and the "fascism" of the GMD, deeming both to be widespread after the dissolution of the first united front in the $1920 \mathrm{~s}$ and during the war against Japan in the 1930s and 1940s. In conclusion, Tang called the traditional heritage a mixed blessing, because the persistent longing for an ecumenical empire triggered radical reactions, ranging from fascist tendencies to anti-fascist (Marxist) currents in which an ecumenical universalism survived, albeit in an unconscious manner. ${ }^{18}$

\footnotetext{
14 The manifesto of 1958 cites Chen Duxiu's attack on Confucianism in the mid-1910s to explain that given such a negation of indigenous traditions, the only remaining (and unsuccessful) option was to try to establish political democracy as a foreign import: Zhang, Zhongguo wenhua yu shijie, p. 42.

15 Tang, Zhonghua renwen yu dangjin shijie bubian, Vol. 10, pp. 155-156.

16 Tang, Renwen jingshen zhi chongjian, p. 266.

17 Tang, Zhonghua renwen yu dangjin shijie bubian, Vol. 10, pp. 160-161.

18 Ibid., pp. 157-158, 161 (on the Youth Party).
} 
In the face of these failures, Tang made clear that a new "consciousness of the state" (guojia yishi 國家意識) was essential for establishing a modern nation-state in China. Yet such a consciousness could only take form in a "conscious, rational" process within the circles of the educated elite, and especially in the spheres of culture and scholarship. Without such awareness of the importance of the state, the vacuum that had emerged due to the dissolution of the traditional clan system and its "consciousness of the family" would be filled by an unrestrained, selfish individualism. The contemporary Chinese literati had, according to Tang, deceived themselves by adhering to the "ideal of the world as one family" (shijie yi jia zhi lixiang 世界一家之理想), but they could not deny the fact that they had indulged in a selfish, "absolute" individualism. As a result of such a pretense, the struggle between political parties became aggravated and led to chaos. ${ }^{19}$

Tang's diagnosis of China's failure in state-building since the mid-19th century rests on a conceptual distinction between (age-old) nation and (modern) nation-state: The old Chinese nation in its dynastic form constituted an empire, but not a modern, territorial nation-state with fixed borders and a constitutional government. The bottom line here is that the Chinese nation had failed to produce a modern political form, and that such an effort-from a global perspective-was now belated. As Tang suggests, it was not until the second half of the 19th century that the quest for a nation-state gradually became the formative "historical experience of the Chinese nation." During this period, the "political consciousness of the nation" evolved-if we are to follow Tang - through nine stages. Each of these was defined by specific political developments carried out by political and intellectual elites: the Taiping Rebellion, the prolonged period of institutional reforms in the effort of "SelfStrengthening," the "Hundred Days' Reform" in 1898, the republican revolution of 1911, the ensuing failure of the constitutional government, the New Culture Movement, the Northern expedition, which led to the formal national reunification of China under the GMD in 1928, the war of resistance against Japan, and finally the communist takeover in $1949 .{ }^{20}$ These nine stages are not to be interpreted as a progressive succession. On the contrary, they represent the continuing failure of Chinese elites to attain an authentic understanding of China's national culture, which, in turn, impeded the effort to establish a democratic nation-state as the adequate political form of the nation.

Tang conceded that there were also so-called "outer" historical factors responsible for the failed nation-state-building in China, but the main thrust of

19 Ibid., pp. 159-161.

20 Tang, Zhongguo renwen jingshen zhi fazhan, pp. 155-176. 
his analysis is focused on "inner," intellectual factors, such as the persistence of misguided concepts of state, nation, bureaucracy, government, party as well as political counseling and planning. The reasons for these misconceptions supposedly pertain to "traditional Chinese thought," Western ideas, age-old political and social habits, but also to the inherent weakness of human nature and "accidental" historical developments. ${ }^{21}$ As a result, present-day China's "problem" was still to be found in the fact that the "nation" was unable to establish a nation-state by democratic measures. ${ }^{22}$

The current situation was particularly bad, because it was characterized by a double failure in state building: The communist rule on the Mainland was, according to Tang, the biggest "outer" obstacle for the establishment of a modern nation-state. Yet, Tang also deemed the progress of the GMD's regime on Taiwan in "democratic constitutional politics" to be "questionable." It marked only the "beginning" of a development towards democratic, constitutional government. Tang detected deficits in democratic legitimacy on the part of the GMD government and concluded that it met the requirements for democratic constitutional government only in a formal respect (based on the constitution of 1947), but not in terms of democratic practice. It was therefore still unclear whether the "political consciousness" of the GMD government and its supporters was actually in full accordance with the "inherent goal" of the political consciousness of the Chinese nation. ${ }^{23}$ This reference to the nation is telling, and even more so with respect to Tang's depiction of China as a cultural nation. The fundamental conclusion is that both the CCP's regime on the Mainland and the GMD's regime on Taiwan were at odds with the eminent political values, ideas, and norms stemming from the humanistic "main current" of China's national culture. It seems, indeed, that Tang was utterly disappointed, both

21 Ibid., p. 178; see also pp. 179-180 (on concepts of political planning and bureaucracy), pp. 180-181, 184-187 (on concepts of the state), pp. 181-182 (on concepts of party and government), pp. 182-184 (on concepts of the nation).

22 Zhang, Zhongguo wenhua yu shijie, p. 36.

23 Tang, Zhongguo renwen jingshen zhi fazhan, pp. 175-177. Tang shared this critical stance toward the GMD government on Taiwan with Taiwan-based liberal thinkers, among them Yin Haiguang and Zhang Foquan. To my knowledge, Tang hardly made any mention of their work. This may be somewhat surprising, perhaps less so with respect to Yin Haiguang. One may surmise that Tang remained silent on Yin's position due to the intense polemics between Yin and Tang's fellow Confucian thinker Xu Fuguan. Another icon of Chinese liberal thought who is also largely absent from Tang's work is Hu Shi. In the eyes of Tang, Hu was one of the chief proponents of a misguided scientism. This view, it seems, deterred Tang from discussing Hu's criticism of the GMD, which had been prominent in China from the mid-1920s to the mid-1930s. 
by the way that the GMD made political use of Confucian traditions ${ }^{24}$ and by the growing attacks on Confucianism on the Chinese Mainland. For him, neither the total elimination of Confucian traditions, nor their integration into a political ideology were adequate incentives for building a modern, democratic state embedded in national culture.

Tang's thoughts on the formation of a modern nation-state in China are centered on two basic insights into the historical and normative dimension of state-building. First, modern nation-states cannot arise from a normative void, but only in the context of a reinterpretation of indigenous cultural and political traditions. ${ }^{25}$ In the Chinese case, this means that the concept of a modern nation-state must absorb normative inputs from a reinterpretation of Confucian humanism. It is against this background that Tang developed the idea that the Confucian "main current" of Chinese culture can only find its authentic historical expression in a modern, democratic state (see Chap. 11 "Modernity and Agency"). Such a modern state was not only to entail a constitutional government and the rule of law, but also to embody the community's ethical substance. Tang even deemed its ethical values worthy of an "aesthetic appreciation." Moreover, the state's "transcendent existence"-i.e. the interconnection of ethical life and moral subjectivity—is worthy of religious reverence. ${ }^{26}$ This line of thought has a Hegelian twist, and Tang to be sure attested to the affinities of his own thought with Hegel's theory of the state as the actuality of ethical life. ${ }^{27}$ But unlike Hegel, Tang attempted to fathom the normative resources of the democratic nation-state by interweaving the historical, Confucian "main current" with the future-bound project of a modern Confucianism in the making. The ethical quality of the state is hence seen as constantly evolving out of the convergence between reinterpretations of the "main current," on the one hand, and the requirements of constitutional government and the rule of law, on the other.

Tang's second insight into the formation of a modern nation-state in China pertains to the concept of the Confucian "main current." As we have seen,

24 For an analysis of the ideological usage of Confucianism by the regime of the GMD, see Chun, "From Nationalism to Nationalizing," pp. 136-141.

25 Tang, "The Reconstruction of Confucianism and the Modernization of Asia," p. 361.

26 Tang, Wenhua yishi yu daode lixing, p. 263.

27 He professed that among Western theories of state, Hegel's theory comes closest to his own ideas: Tang, Wenhua yishi yu daode lixing, p. 254. On Tang's critique of Marxist and utilitarian concepts of state, and of contract theories and organic concepts of state, see Tang, Wenhua yishi yu daode lixing, pp. 217, 238-253, and Tang, Zhongguo renwen jingshen zhifazhan, pp. 198-199; see also Chap. 11 "History and Normativity." 
he deemed an authentic understanding of the "main current" crucial for the foundation of a democratic nation-state. Conversely, the reinterpretation of Confucian traditions must be guided by concepts of a modern state and society. A traditionalist reconstruction of Confucianism as a holistic force that conflates ethics, politics, law, and aesthetics is unwarranted because it would be detrimental to the formation of modern society. Consequently, Tang, as we have seen, introduced the differentiation of moral, aesthetic, political, and social dimensions to Confucianism and on this basis related Confucianism to the concept of constitutional democracy. The Confucian tradition is therefore not to be preserved in its entirety. Tang indeed considered the fragmentation of Confucianism to be inevitable, and this also pertained to the humanistic "main current." In fact, it is under this premise that China's national culture is to serve as the point of reference for the renewal of ethical life in modern China.

For the time being, however, a "democratic Chinese nation-state" which lives up to the official name of the new state- "Republic of China" (Zhonghua Minguo 中華民國)—was still in the making. ${ }^{28}$ Eventually, as Tang maintained, "Zhonghua" would exemplify "the continuity of China's historical and cultural traditions" upheld by the "nation," "people," or "modern citizenship" within a modern state. ${ }^{29}$ In spite of all the setbacks since the mid-19th century, Tang was still unshaken in his belief that the progress toward a modern Chinese nation-state will finally prove to be irresistible. The source of this optimism was ultimately his conviction that, so far, the efforts of state-building had been undertaken without an adequate reinterpretation of the main current of Confucianism. ${ }^{30}$

\section{The State and Individual Self-Fulfillment}

Tang considered the role of the state mainly from the perspective of the individual's quest for self-fulfillment. The state is to safeguard the freedom, safety, and livelihood of its members, and to secure the conditions for their ethical life. ${ }^{31}$ But the state must not be permitted to subject individuals to a dogmatic,

\footnotetext{
28 Tang, Zhongguo renwen jingshen zhifazhan, pp. 175-176.

29 Ibid., p. 156.

$30 \quad$ Ibid., pp. $175^{-176 .}$

31 Tang used several terms to refer to the notion of "ethical life" as he anticipated it for a modern China: "moral way of life" (daodexing shenghuo 道德性生活), “moral refinement and cultivation” (daode xiu yang 道德修養), but also, depending on the context, “culture”
} 
petrified form of ethical life, for this would prevent them from actualizing their innate potential to attain self-fulfillment in moral intuition. Tang's concept of the (future) political state as an embodiment of ethical life obviously requires that a distinction be made between the actual ethical life at a certain stage in history, on the one hand, and the moral subjectivity of individuals who are embedded in ethical life, but not predetermined by it, on the other. ${ }^{32} \mathrm{~A}$ political state which subjects its citizens to dogmatism fails to live up to the true idea of a state, because it suppresses moral subjectivity. Consequently, Tang conceived of an ideal state which embodies an ethical relation, without however suppressing moral subjectivity (i.e. "moral reason"). Against this backdrop, he developed his thoughts on human freedom. By freedom, he understood moral and spiritual self-fulfillment, and thus the authentic selfhood of the individual. This notion seems to harken back to Western concepts of positive freedomi.e. the freedom to participate, to cultivate one's personality etc.- and negative freedom-i.e. freedom from undue intervention by the collectivity and most of all the state. But Tang explicitly claimed to follow a Confucian tradition of identifying freedom as the freedom to build one's personality and character and thereby attain the "true self" of an ethical person. Although the modern Chinese term for freedom, ziyou 自由, was unknown to pre-modern Confucianism, Tang listed expressions like "pursuing the perfection of one's personality" (qiu renge de wanman 求人格的完滿), “self-fulfillment” (zi cheng 自成), or “self-pursuit" (ziqiu 自求) as identical in meaning. ${ }^{33}$

The notions of freedom as selfhood and the self-realization of the individual are at the basis of Tang's discussion of different kinds of individual and collective freedom. The individual's arbitrary freedom, political liberties, and the collective freedom of families, communities, societies, nations and states are all conceptualized in relation to the notion of freedom as the moral, spiritual, and intellectual self-realization of individuals. ${ }^{34}$ Significantly, Tang assumed that the individual rights and liberties that have developed in Western societies did not perforce contradict a renewed Confucian notion of freedom as the self-realization of individuals in an ethical context. He even took this

(wenhua 文化), “(objective) spirit” (jingshen 精神) or "spiritual substance” (jingshen shiti 精神實體). With respect to morals in the traditional sense of an ethos, he speaks of fengsuxiguan 風俗習慣; see e.g. Tang, Wenhua yishiyu daode lixing, p. 601. Tang, Wenhua yishi yu daode lixing, p. 610.

33 Tang, Renwen jingshen zhi chongjian, p. 378; see also p. 346.

34 On Tang's theory of freedom, see Tang, Renwen jingshen zhi chongjian, pp. 330-346; see also Tang, Wenhua yishi yu daode lixing, p. 6 o6. 
assertion one step further, trying to show that Confucian concepts of tolerance and solidarity have a vital function as social and ethical safeguards for individual liberties. ${ }^{35}$ Here, "tolerance" (duliang 度量) entails the willingness to brook another person's choice of values and ideals. Solidarity, on the other hand, requires the willingness to support other individuals in their attempt to realize their choices of values and ideals and thus to actively help them build their ethical personality, thereby displaying one's "humane mind" (ren xin 仁心). ${ }^{36}$ It is on this basis that Tang explored how an individual and a collective consciousness of solidarity take shape within the contexts of the family, the state, and the international order of nation-states.

With respect to individuals, Tang did not conceptualize tolerance and solidarity as either civic duties or civic virtues, but, significantly, as expressions of individual freedom. Tolerance and solidarity are seen as requirements for the individual's freedom to strive for self-realization, and therefore as indispensable assets of a community whose individual members are free to choose their own path towards self-realization. Tolerance and solidarity are thus connected to the actualization of freedom, and specifically to the individual's expression of selfhood. In practicing tolerance and solidarity, individuals actualize their essentially ethical nature and, at the same time, display their freedom by acting on their ethical mindset. The crux of this conceptualization of freedom consists of the interrelation between individual rights and liberty, on the one hand, and renewed morals or Sittlichkeit (i.e. substantial freedom), on the other. Tang understood individual rights and liberty as a precondition for the (Confucian) renewal of morals, whereas renewed morals, in turn, serve to safeguard individual rights and liberty within the political community.

Tang was probably aware of the fact that there are counterparts in Western political thought that match, at least in part, his own reasoning, such as theories of civic virtues in the traditions of republican thought. ${ }^{37}$ One may also find

35 Here and in what follows: Tang, Renwen jingshen zhi chongjian, pp. 343-346.

36 Tang did not introduce a modern Chinese word for "solidarity," possibly because there was no such neologism established yet. Depending on the context, he relied instead on a number of related terms such as "responsibility" (Tang, Wenhua yishi yu daode lixing, p. 293), "moral responsibility" (Tang, Wenhua yishi yu daode lixing, pp. 295, 297), "sense of responsibility" (Tang, Wenhua yishi yu daode lixing, p. 293), "love for the family" (Tang, Wenhua yishi yu daode lixing, pp. 295, 297), "love for the state" (Tang, Wenhua yishi yu daode lixing, pp. 295-298) "consciousness of love for the state" (Tang, Wenhua yishi yu daode lixing, p. 295), "loyalty toward the state" (Tang, Wenhua yishi yu daode lixing, p. 298).

This line of reasoning about republican thought had been explicitly pursued, for example, by the political scientist Xiao Gongquan who in 1937 had discussed the requirements 
commonalities with contemporary communitarian ideas about the relationship between individual liberty, rights, and civic virtues. But more significant is perhaps the fact that Tang's concept of rights is similar to Hegel's, which suggests that there is no real freedom in a community that does not recognize the subjective rights of individuals. In Tang's view, China's political systems in the past were characterized by a traditional ethos and the strong tendency to subdue the subjectivity of the individual. ${ }^{38}$ Curiously enough, Tang's critical review of Confucian traditions is not abetted by his own system of a philosophy of law. He also did not bother to criticize Western philosophies of law, let alone try to improve on them by synthesizing Western and Eastern ideas. The notion that the system of law is the modern institutional precondition for the existence of morals in the realm of the state, which is of great importance to Hegel, ${ }^{39}$ is simply implied by Tang. Rather than discussing it in detail, he merely anticipates it by referring to a hypothetical Chinese present that is characterized by the rule of law and constitutional government. His texts thus lead to the impression he is writing about an extant liberal democracy in China.

As we have seen, Tang proposes a "Confucian" interpretation of tolerance and solidarity as manifestations of freedom that are indispensable for guaranteeing constitutional liberties. The assumption here is that these liberties would be far too fragile in a political reality where citizens would respect them solely out of individual interest or due to the power of law. What is necessary is a degree of voluntary obedience in the form of a willingness to respect the constitutional rights of others. This entails a habitual, as well as culturally and morally stabilized, willingness of individuals to comply with the constitutionally guaranteed individual rights of others. This does not, however, mean that such compliance should solely emerge from traditions or habits, thus effectively downplaying the importance of actively sought-after moral consent among individuals. As Tang saw it, such a constellation of habitual compliance would merely amount to the "lowest stage" of the "legal consciousness."40

for constitutional rule in China in an article entitled "The Preparations for Implementing Constitutional Government” (“Shixing xianzheng zhi zhunbei 實行憲政之準備”; published in the Da Gong Bao 大公報 on May 2, 1937). Xiao had observed that Western scholars consistently claimed that constitutional rule required "good habits" (liang hao xiguan 良好習慣) from the people and could not rely on legal regulations by the government alone; see Xiao, Xianzheng yu minzhu, p. 15.

38 Tang, Wenhua yishiyu daode lixing, p. 6og.

39 On Hegel, see Ritter, Metaphysik und Politik, p. 309.

40 Tang, Wenhua yishiyu daode lixing, p. 6og. 
Consequently, Tang envisioned a higher stage of legal consciousness where the process of forming law-abiding habits among the citizenry is put in place by the workings of the rule of law itself. This would make it "increasingly unlikely" that people indulge, without restraint, in striving for power. ${ }^{41}$ Legality is thus said to be an important cause in the formation of the individual's ethical mindset within political society. Yet this ethical mindset cannot be fostered by legal institutions alone..$^{42}$ As this foundation is not strong enough, the rule of law and a constitutional guarantee of individual rights require the citizen's "moral refinement and cultivation" (daode xiu yang). ${ }^{43}$ However, this is not to be mistaken as a claim to conceptualize morality as the cause of legality. It is rather a matter of relating the individual's moral formation to the state and the legal system, thereby embedding the rule of law in social reality. That said, Tang cited "law" ( $f a$ 法) and "rites" (li 禮), two traditional terms, and infused them with new meaning to flesh out the idea that a community's ethical and cultural contexts can never find full expression in a universal and abstract "legal consciousness" ( fa yishi 法意識). To fill out this legal consciousness, a "consciousness of rites" (li zhi yishi 禮之意識), meaning an ethical disposition, must take shape among the citizens. It follows that the system of law cannot be detached from the community's morals, but should instead be seen as shaped by discourses and practices related to ethical, social and cultural contexts. Tang understood the idea of morals and ethical disposition in a modern, Hegelian sense as something which does not submit the moral subjectivity of individuals to the rule of an overbearing tradition or ethos. Quite to the contrary: The ethical contexts of the community must stand the test of moral subjectivity and need not be accepted blindly. The "consciousness of rites" is therefore as much the result of the subjective morality of individuals as it is of extant morals and traditions. ${ }^{4}$

\section{State and Society}

On the basis of conceptualizing individual rights as requirements for the Confucian renewal of morals, Tang interpreted the individual's ethical relations at the stages of family, communal associations, and social sectors. These ethical relations were to be understood as an expression of the individual's

\footnotetext{
41 Tang, Renwen jingshen zhi chongjian, p. 396.

42 Tang, Wenhua yishiyu daode lixing, p. 614.

43 Ibid., p. 612.

44 Ibid., p. 614.
} 
freedom to develop his or her personality and aspire for self-fulfillment. ${ }^{45}$ The initial stage is characterized by the individual's embedding in the family. According to Tang, in order to experience the family as a sphere of freedom, individuals must not conceive of family relations solely in terms of blood ties or of securing their economic subsistence by cooperating within the family. ${ }^{46}$ The family belongs to the sphere of freedom only insofar as it can be interpreted by individuals as an ethical relation that enhances their chances of achieving selffulfillment through moral "refinement." ${ }^{\text {"7 }}$ The moral relation par excellence is that of a child and his or her parents. Tang insisted on an interpretation of "filial piety" (xiao 孝) as a moral idea in the context of modern societies where familial ties tend to disintegrate. He thus argued that the physical presence of the parents was not an indispensable precondition for practicing filial piety. ${ }^{48}$ His insistence on filial piety in the absence of the parents is somewhat typical for his individualistic interpretation of traditional norms and practices: In the absence of parents, the modern individual has to consciously choose to practice filial piety, create a different form for the practice, and reinterpret its ethical meaning. The individual's moral subjectivity will therefore not be overwhelmed by the actual practices of traditionalist forms of ethical life.

The wider spheres of communal ties and social relations also belong to the sphere of ethical life, although not in the same degree or kind. Tang distinguished between these two spheres systematically, as well as from a historical perspective. In communal associations, the members meet each other "immediately" on the basis of shared ethical values, or territorial, familial, or emotional ties-i.e. without the intermediation of "outer" purposes like common economic interests. Tang suggests that Chinese communities typically include the family and the clan, but also organizations of alumni, members from the same birth-place, academics, participants in "poetry and wine gatherings," and even secret societies. Tang presumed that these quasi-natural associations were more common in China than in the West, and that some of them may continue to form important contexts of individual self-realization in Chinese

45 The sequence of these stages is loosely in line with the topical arrangement of chapters in Wenhua yishi yu daode lixing, which is most likely inspired by Hegel's Philosophy of Right and hence corresponds to the idea of retracing the stages of the development of individual freedom (in: family life, economics, politics, philosophy and science, art and literature, religion, morality, physical exercise, military training, law, education).

46 Tang, Wenhua yishi yu daode lixing, pp. 67, 113 .

47 Ibid., p. 66; see also pp. 111-113.

48 Ibid., p. 109. 
modernity. ${ }^{49}$ This continuity is said to be conducive to reducing negative sideeffects of social modernization. However, Tang did not provide any sociological explanation for this proposition, and hence simply implied that some traditional formations may resist the forces of modernity.

Yet Tang's position is not aptly described as traditionalist. He strongly insisted on the importance of the sphere of civil society which is fundamentally different from communal ties. Even though Tang did not elaborate on the Hegelian notion of civil society ("bürgerliche Gesellschaft") as the sphere of law in which "abstract" legal subjects entertain contractually organized relations, he still implied the significance of a civil society. Yet he hardly used the general term "society," preferring instead the pluralizing concept of "social associations" (shehui tuanti 社會團體). Social associations are to be understood as associations emerging from the shared interests of their members. Such outer, intermediate interests or purposes are thus instrumental for the existence of these associations. What Tang actually had in mind here were the "usual social groups and organizations of a Western, modern type," such as industrial organizations. ${ }^{50}$ As his use of the term "Western" indicates, he claimed that there had been no such organizations in pre-modern China or, for that matter, a notion of society comparable to Western concepts of civil society. ${ }^{51}$ In order to catch up with the West, China's modernization would therefore require the development of a civil society as a sphere regulated by law and organized according to contractual relations between abstract legal subjects and the logic of division of industrial labor.

Tang's modern Confucian notion of individual self-realization obviously does not condemn the pursuit of individual self-interest, as was predominantly done in traditional Confucian ethics. In a modern state, individuals have no choice but to participate in the sphere of the civil society in some form or another. Moreover, it is in this sphere where the individuals encounter each other first and foremost as legal persons. As Tang sees it, individuals consequently acknowledge each other solely in regard to the "single aspects" of their

Tang, Zhongguo renwen jingshen zhi fazhan, pp. 193, 206.

$50 \quad$ Ibid., pp. 193, 206: Moreover, Tang mentioned "the organizations of class interests" and those "religious organizations" that rely on a "transcendent belief in an abstract manner" (ibid. p. 193); at another point, he sketched the spectrum of social associations by referring to scientific societies, welfare organizations, as well as political, economic and military associations. He even listed bands of robbers, following here the rationale that they also function upon principles of cooperation and a division of labor to achieve common goals; see Tang, Wenhua yishi yu daode lixing, pp. 205-207. 
specific economic functions, social roles, and legal status. There is hence no need for them to recognize each other as ethical persons or individuals with a background of particular family ties, unique character traits, etc. By definition, the ethical values may be realized in civil society within only a very restricted scope, ${ }^{52}$ and the human being's "moral reason" also can be realized to only an "utterly minor degree." 53

Tang contrasted this perspective to China's traditional society and its social and political thought, concluding that the absence of a concept of civil society corresponds to pre-modern China's lack of a concept of constitutional state. The modern, constitutional state not only has to deal with individuals and certain communities, but also with a broad, competitive sector of industrial and commercial organizations which are established on the basis of a system of civil law-an undertaking unknown in imperial times. ${ }^{54}$

For Tang's modern Confucianism, individuals are embedded in spheres of ethics and rights (legal life) by belonging to families, communities, and civil society. These associations constitute contexts for the individual's moral selfrealization. However, Tang presumes that the integration of these spheres in a way that successfully avoids suppressing the manifold expressions of particularity can only be achieved in a (future) constitutional state which embodies ethical life. What is at stake in this Hegelian outlook is a concept of a modern state that incorporates a democratic government, the rule of law, as well as a renewal of Confucian morals. In Tang's view, traditional Confucianism was in no position to achieve this integration.

Modern Confucianism hence needs a renewed concept of ethical life that does not contradict the basic tenets of constitutional government and the rule of law. As we have seen, a key element of this renewal is the reconceptualization of ethical life in the broad sense as a sphere of individual freedom. The individual's moral subjectivity thus must not be subordinated to social and religious traditions and a supposedly sacred imperial order. From the perspective of moral subjectivity, Tang discerned the foundation of the individual's attachment to the family and the state in a spirit of solidarity, i.e. a "benevolent mind" (ren xin 仁心) and a "public spirit" (gong xin 公心). Individuals do not attain such a spirit by blindly submitting themselves to a powerful ethos or tradition and having their moral subjectivity overwhelmed. Rather, the spirit of

$5^{2} \quad$ Tang, Zhexue gailun, Vol. 22, pp. 555-556.

53 Tang, Zhongguo renwen jingshen zhifazhan, p. 223.

54 The "Western, modern organization of the state" strives, according to Tang, to have "social groups" join in building a unity: Ibid., p. 206. 
solidarity has to be seen as a manifestation of the freedom of the "moral self" (daode ziwo 道德自我). In fact, as Tang suggests, the individual's consciousness of the family and the state arises exclusively from "moral reason" (daode lixing 道德理性), which, in turn, is ultimately anchored in human nature and "the way of Heaven." 55

With its focus on the individual's moral subjectivity, Tang's idea of the modern state reflects the enormous conceptual shift which occurred when the Republic of China was established in 1912. In contrast to the old dynastic state and its ritual order, the new state was not seen as representing the sacred sphere of Heaven. Instead, it was fully accessible by the political will of its citizens, at least in principle, and thus individuals no longer faced a politically intangible "Heavenly" order. Modern Confucianism fully consummates this shift by interpreting the state as a manifestation of human self-realization. The modern state is hence an actualization of human reason, or in Tang's words: "an objectification of the reasonable self (lixing ziwo zhi keguanhua 理性自我 之客觀化)." 56 Tang therefore regards the existence of the state as a demand from the "unified, reasonable self of our inwardness" which strives for "objectified manifestations [of itself]." ${ }^{57}$ As he bluntly states:

According to our theory, [the reason] for which the state exists is originally not its instrumental value of actually enabling the individuals to achieve [their] interests, but [the fact that] it is the objectified manifestation of men's unified reasonable actions. The direct goal of the state's

55 Tang, Zhonghua renwen yu dangjin shijie bubian, Vol. 10, pp. 162-163. Tang also at times referred with a Buddhist vocabulary to the higher unity formed by the freedom of the individual will and the general will of the state embodying ethical life: see Tang, Wenhua yishi yu daode lixing, p. 256.

56 Tang, Wenhua yishi yu daode lixing, p. 238. Tang strongly rejected the theories of Hobbes and Marx "on the origin of the state" and added that it was these two thinkers who departed most clearly from his own theory on the origin of the state. With respect to Marx, he disagreed with the assumption that the state was evolving out of armed struggles between nations or people only to become, thereafter, a "relation of class rule." As for the theory of Hobbes, Tang took issue with the view that men overcome their natural state of existence out of fear from each other and agree on the terms of a contract by conceding their own rights to the sovereign rule: Ibid.; see also Tang, Wenhua yishi yu daode lixing, p. 238; Tang, Zhongguo renwen jingshen zhifazhan, p. 214; Tang, Renwen jingshen zhi chongjian, p. 392.

Tang, Wenhua yishiyu daode lixing, p. 218. 
existence consists in fulfilling the demands of the objectification of these reasonable actions. ${ }^{58}$

In accordance with this, Tang's Confucian civil theology identifies the state, in its highest form, as the political form fully embodying human reason and facilitating the individual's quest for self-fulfillment in moral intuition. Since it is "Heaven" which reveals itself in and through human intuition, the state retains, as it were, the potency to represent the sacred, albeit in an intermediate way. Tang's hypostasis of the modern state is most likely a reaction to the weakness of the ill-fated republican state in China and serves a compensatory purpose. After all, the republican state, which failed to establish political unity after 1912, was depleted of any religious meaning. It was perhaps no coincidence that a practical-minded ruler like Yuan Shikai was among those who clearly recognized the grave effects that the swift dissolution of the imperial state cult and its rituals and ceremonies would have on the young republic. But Yuan's attempt to reinvent official rituals of Heaven within the republican state in 1914 was short-lived and unsuccessful. ${ }^{59}$ Henceforth, the Chinese state seemed to represent nothing but mundane political interests driven by competing military, economic, and social forces. It is this secularizing vacuum of representation that Tang's civil theology attempted to fill by conceptualizing a constitutional state embodying ethical life. The modern state was thus related to the individual's moral subjectivity and the quest for self-fulfillment in "inner sagehood."

\section{The World Order of "Ecumenical States"}

For Tang, the formation of modern nation-states was an ongoing historical process of global dimensions. Any swansong for a world order of nation-states would therefore be premature. Tellingly, he categorized a peaceful world order in which nation-states form the basic elements as an ideal. ${ }^{60}$ According to Tang, the two major criteria for evaluating such a world order are international

$5^{8}$ Ibid., p. 242. In the same context, Tang explained that the theories of Hume, Bentham, and Mill, who strongly emphasized individual interests, were insufficient in terms of an explanation of the origin of the state. They may rather explain the persistence of the state, i.e. its courant normal which includes the "subjective mental state" of people in everyday life with regard to the state: Ibid.

59 Zarrow, After Empire, pp. 230-239.

6o Tang, Wenhua yishi yu daode lixing, p. 301. 
peace and "international cultural cooperation,"61 whereas the idea of global political, social, and economic justice plays a minor role.

Tang was convinced that international peace, understood as the eschewal of wars between nation-states, cannot be guaranteed by international law alone. It requires, in addition, a willingness of individual and collective actors to voluntarily refrain from the use of force, to engage in cooperation, and to act in solidarity across national borders. This willingness should further entail the implementation of international law. One of the crucial questions, therefore, is how solidarity across national borders may be evoked and sustained. The idea of a universal moral law as such cannot function as a source of solidarity within the world order of nation-states, because, as Tang observed, such a universal moral law had no stable foundation in historical reality. As long as the moral duty to act in transnational solidarity solely pertains to an abstract, universal humanity, it would remain fragile, even if bolstered by a "sense of responsibility," and never equal the strong display of solidarity within nationstates. According to Tang, this fragility is due to the fact that, other than the concrete, particular idea of fellow citizens within a nation-state, the abstract idea of humanity does not pertain to concrete institutions and structures. The actual content of the idea of humanity is hence meager in comparison with the idea of membership in a nation-state. Besides, the responsibility for humanity remains abstract because the actors lack a "method" to actually live up to it, even though they might be willing to do so. ${ }^{62}$ Tang consequently summarized this constellation with the brief phrase: "Whoever does not love the state, will in any case be unable to love the ecumene."63

As a source of international solidarity, Tang identified cultural patriotism with a cosmopolitan outlook. ${ }^{64}$ This outlook entails an explicit distinction

61 Ibid., p. 298. Tang was not the first Chinese political thinker to posit that the realization of international peace was intrinsically related to the nation-state. In his The Three Principles of the People, Sun Yat-sen had already assumed that international peace required the inner stability of the nation-states and hence could not be imposed on the world to the neglect of the importance of nation-states. On Sun, see Fröhlich, "Der Machtstaat in Sun Yat-sens Drei Volksprinzipien: Nationalismus und Expertokratie in der chinesischen Republik," pp. 98-99.

62 Tang, Wenhua yishi yu daode lixing, p. 293.

63 Tang, Zhonghua renwen yu dangjin shijie bubian, Vol. 10, p. 161. It should be noted here that the term "love" indicates a reference to "patriotism" (in Chinese: aiguozhuyi 愛國主義).

64 In this context, it becomes clear that the original title of the manifesto of 1958 has a programmatic ring: "A Manifesto with a Message for International Personalities Concerning Chinese Culture. Our Joint Understanding of Research about China as well as the Future of Chinese Culture and World Culture." 
from notions of a global society as a source of international solidarity. Tang is indeed in agreement with Hegel's diagnosis about the inevitable tendency of industrializing societies to expand and colonize other countries. Hegel assumed that increasing productivity regularly compels civil societies to open up new markets in colonized countries and thus push for a global society ${ }^{65} \mathrm{In}$ a similar manner, Tang perceived a danger stemming from the tendencies of social and economic forces to gradually seize hold of the world and weaken the nation-states. For Tang, it was a tell-tale sign that such a creeping quasisocialization of the world order is obscured by the notion of a universalistic "consciousness of the ecumene" (tianxia yishi), which is abstract insofar as it does not contain the concept of a (nation-)state.

As long as this false universalism persists, there will be no awareness of the fact that colonialist expansions are triggered by socioeconomic productivity and may only be curbed in a world order of nation-states. According to Tang, the consequences of such a misconception are severe, because uncurbed expansion remains at the disposal of specific types of socioeconomic organization, namely, those based on instrumental rationality and which tend to conquer "others." Tang warned that the notion of a universal ecumene inevitably serves to conceal an "absolute egotism" which threatens to annihilate humanity. ${ }^{66}$ As the main beneficiaries of this cover-up, Tang discerned globally active socioeconomic players who push nation-states into "imperialist politics." ${ }^{67}$ Tang did not clearly identify the historical context of his diagnosis, but it does not seem far-fetched to suppose that China's experience in the international opium trade and its wars in the 19th century likely played an important role in shaping his view that ruthless economic actors were capable of exerting considerable influence over their country's foreign policy.

Tang did not believe that the weakening of the state in a dynamic process of socioeconomic development was a matter of historical necessity. A modernizing community might still avoid such a course and instead strive for a superior "ecumenical state" (tianxia guojia 天下國家) which embodies a transnational type of solidarity. By introducing the notion of the ecumenical state, Tang perhaps referred to the speculation about the world order represented in The Great Learning (Da xue 大學). However, he moved beyond such speculation by focusing on the problem of fostering patriotism within a modern state

65 Hegel, Philosophy of Right, pp. 189-191 (§246, §248); see also Ritter, Metaphysik und Politik, p. 222.

66 Tang, Zhonghua renwen yu dangjin shijie bubian, Vol. 10, p. 162.

67 Tang, Zhongguo renwen jingshen zhi fazhan, pp. 223-224; see also Tang, Wenhua yishi yu daode lixing, p. 300. 
without unleashing nationalist fervor. From this perspective, patriotism is neither restricted to the narrow interests of strengthening one's own nation-state, nor to a merely emotional attachment to the state. It rather calls on individuals to exercise the cosmopolitan virtue of acknowledging that the patriotism expressed by the people of other nations is as virtuous as their own patriotism. Individuals, hence, are to respect the moral responsibility of others for their state and consider their patriotism as a reasonable cause of the existence of other states. ${ }^{68}$

At least the basic outlines of these ideas resemble European and American ideas about the foundation of a mutual recognition between nations or peoples. Michael Walzer reflects on such ideas when referring to Isaiah Berlin's interpretation of Herder, which centered on a "core principle of reiterative universalism." Such universalism does not posit that there exists a universal history following a "covering law" (as is the case in Christian and Hebrew traditions, but also in Hegelian and Marxist philosophy of history). In contrast, reiterative universalism relies on the particularistic view that the historical experience of nations should be understood in terms of narratives or histories, but not as a universal history which accords to unitary principles or laws. If notions of a covering law (such as "repression is always wrong") are to be considered at all, then only in the sense that such laws are exemplary for a multitude of particular historical experiences and hence can be considered repetitive. ${ }^{69}$

Tang envisioned the formation of international solidarity to take place within the nation-states and their national cultures, provided that they were orientated toward cosmopolitan patriotism. It is only in such a particularistic context of solidarity that a collective will to curb the socioeconomic sector and, therein, to guarantee preconditions for implementing international peacekeeping and international law might eventually emerge from within the nation-states. Whereas the political form of the nation-state is to remain unchanged within the (future) world order of international peace, the national cultures must entail a dynamic moment and foster the formation of

68 Tang, Wenhua yishi yu daode lixing, pp. 296-298. Tang assumed that the individual's cosmopolitan patriotism emerges from a gradual formation of his or her "consciousness" of the family, the state, and the ecumene-as originally indicated in The Great Learning. Such a formation will eventually lead to the manifestation of the "nature of the Heavenly mandate” (tianming zhi xing 天命之性); see Tang, Zhonghua renwen yu dangjin shijie bubian, Vol. 10, p. 162.

69 Walzer, Nation and Universe, pp. 509-515, 532-533, 551; on Berlin/Herder see p. 551; on the notion of a covering law, see pp. 524-525. 
cosmopolitan patriotism (instead of nationalism). Tang referred to this transformation by the term "ecumenical states," which are to maintain a cosmopolitan-patriotic "culture, education and morality." 70

An accentuation of culture, education, and morality in the context of international peacekeeping can also be found in the Confucian thought of imperial China. Yet, Tang removed the "ideal" of a peaceful world order from its attachment to the (Chinese) empire and related it to the idea of a global ecumene made up of a pluriversum of modern nation-states. ${ }^{71} \mathrm{He}$ thus distinguished his own conception of ecumene from earlier Confucian speculations. On this basis, his outlook was rather sober and only loosely related to the traditional discourses about the civilizational centrality of the Chinese ecumene. He actually never identified China as the sole center: After all the states in the world have begun to strive for "progress in culture, education and morality" and renounced the use of force, except for the immediate purpose of selfdefense, a global situation might emerge in which nation-states that possess a "comparatively progressive culture, education and morality" will be "gradually" respected as "central states." ${ }^{72}$ The exemplarity of these culturally and ethically advanced nation-states would be due to their willingness to pursue, on an international level, a course of action that is orientated toward peace, cooperation, and solidarity.

Although Tang had no intention of proclaiming certain nation-states or national cultures to be the bearers of cultural supremacy, his conception is not entirely free of such insinuations. Moreover, his notion of a "main current" in national culture unwittingly encourages, as we have seen, tendencies to reify the Chinese nation and its culture. It is regrettable that he did not discuss these implications, even more so because he refrained from portraying Chinese culture as a device for healing the modern world. Such an outlook

70 Tang, Wenhua yishi yu daode lixing, p. 301.

71 Here, it is obvious that Tang's conception of peace is only very loosely in line with the Kantian idea of eternal peace. For a comparative examination of Tang's and Kant's conceptions of peace: see Huang, "Tang Junyi de yongjiu heping lun—shiye yu juxian," pp. 87,95 .

72 Tang, Wenhua yishiyu daode lixing, pp. 301-302. This notion of "central states" or "middle states” (zhongxin guojia 中心國家) clearly evokes the period before the unification of the empire in China, when the royal house of the Zhou was to reign over statelets in the central plane that were labeled as "middle states," thus forming a cultural and military realm. Tang refers in this context explicitly to the Mencius and the Xunzi and introduces the ancient term "kingly way" (wang dao 王道) to denote an ideal way of ruling (a term, by the way, that also figured prominently in Sun Yat-sen's and Qian Mu's thought on the Chinese nation and its culture): Ibid. p. 302. 
could not be reconciled with his concept of modernization as a global process which is characterized by an inevitable and inextricable split between spiritual inwardness and individual subjectivity, on the one hand, and an increasingly instrumentally ordered, alienating objective world, on the other. According to Tang, the elimination of all forms of such alienation within a unified nation, a unified global ecumene, or some future state of "great uniformity" (da tong) is beyond the reach of humanity.

For further clarification of Tang's idea of ecumenical states, it is instructive to briefly consider, by way of comparison, Fichte's etatism. In Fichte's philosophy of history, the culturally advanced state is, similar to Tang's view, a manifestation of the highest form of human culture. Unlike Tang, however, Fichte assumed that this state unintentionally strives for "the foremost purpose of humanity" ("den allerersten Zweck der menschlichen Gattung"), while pursuing its own interests. Fichte thus claimed, in fact, that the outcome of the forceful expansion of the state's cultural potency onto its European neighbors, and even more so onto territories overseas, did not necessarily run counter to the purposes prescribed by the divine "plan for the world" ("Weltplan"). The global "peoples' republic of culture" ("Völkerrepublik der Kultur"), which Fichte posited in his philosophy of history as a goal of humanity, seems at first glance to be in line with Tang's notion of a global community of ecumenical states. But Tang and Fichte held different views on the formation of such a community; after all, Tang did not support the Fichtean idea that the state, while striving for power internationally in promoting its own interests, unwittingly works towards the ultimate good in history. Fichte was convinced that the actual, higher purpose of humanity (which is to become manifest in religion, science, art, and ethics) cannot be directly turned into the purpose of state action. The state may contribute to realizing the purpose of humanity only by implementing the conditions for its realization..$^{73}$ Tang's future ecumenical states would, much like the superior state in Fichte's scheme, assume a position of power among the nation-states, but they would use their superior power only for the purpose of self-defense, and not for power politics or imperialist expansion. Thus, Tang did not follow Fichte's speculation about the formation of a peaceful future world order on the basis of unintentional state action. He assumed, on the contrary, that only if the state works for the realization of international peace, cooperation, and solidarity, intentionally and guided by an advanced national culture, does it qualify as an ecumenical state.

73 For the quoted expressions and the analysis of Fichte's theory of state, see Fetscher, "Johann Gottlieb Fichte," pp. 182-184. 
Tang's "ecumenical state" is evidently a futural political concept. Nevertheless, it may be applied to the present as a normative criterion, even though there are currently no "ecumenical states" in existence. Accordingly, Tang reached a very sober conclusion in 1974 with respect to the current world order. He stated that even though many people worldwide long for a unified "world government" (shijie zhengfu 世界政府) and a “world state" (shijie guo 世界國), the dominant tendency in military, political, and economic matters since the First World War was one of division, in spite of such ideas as the League of Nations, a world government, and a world state. ${ }^{74}$ As regards the United Nations, Tang labeled it a forum which had already lost its original meaning and "authentic value" in the midst of contending nation-states. He deemed the notions of world government and world state therefore to be merely remote ideals. ${ }^{75}$

The tendency towards separation in international politics following two world wars was further evidenced by the fact that a number of new states had already been founded or were about to emerge in Asia and Africa. Tang believed that there was no historical precedent for this development and emphatically rejected any analogy that might be drawn with the constellation of the Warring States period in pre-imperial China. ${ }^{76}$ With regard to the global economy, Tang detected a similar tendency toward separation in the fact that the economies of advanced Western nations were increasingly challenged by rising nations, such as a rapidly industrializing Japan, oil producing Arab countries, and developing Third World countries. Besides, Tang referred to a global tendency towards the dissolution of centers of military power. The "core" of military power-i.e. nuclear weapons - was no longer an exclusive matter of the Soviet Union and the United States, for France, the PRC, and India had become nuclear powers and more states would certainly follow suit in the future. ${ }^{77}$

Based on his interpretation of the history of the 2oth century, Tang was convinced that a concentration of coercive means and military power, even if it were to be achieved by a global community of nations, would not provide a way to world peace. On the contrary, he foresaw that the realization of world peace must entail, on the one hand, a renouncement by existing nation-states of the suppression of ongoing global tendencies towards further "separation"

74 Tang, Zhonghua renwen yu dangjin shijie, Vol. 2, pp. 409-410.

75 Ibid., p. 411. Already in 1953 Tang introduced the concept of a "world state" (shijie guo) explicitly as an "ideal" which should help to avoid a Hegelian hypostasis of statehood. In the same vein, he introduced the "ideal of an ecumenical great peace which transcends the state;" see Huang, "Tang Junyi de yongjiu heping lun—shiye yu juxian," pp. 82, 96-97.

76 Tang, Zhonghua renwen yu dangjin shijie, Vol. 2, p. 410.

77 Ibid., p. 411. 
(fensan 分散) into new nation-states, and, on the other, gradual progress within nation-states in terms of "culture, education and morality."78 This view of advancement towards a peaceful world order is certainly highly optimistic, but it is not to be mistaken for a blind belief in historical progress. Tang neither set out to detect signs of historical progress in every corner of the world or at every stage of historical development, nor did he expect human history to culminate in the realization of the good. His assumption that cultural and moral progress first become manifest in ecumenical states rather serves the purpose of highlighting a possible outcome of human history, while, at the same time, raising awareness that the course of history is not inescapable.

There is thus leeway for critical thinking about political reality. Consequently, Tang's reflection about world order remains skeptical about positions of "realism" which tend to downplay the need for normative judgments about the political reality of world order, which is to be taken for what it is. By referring to the future world order of ecumenical nation-states as an ideal, Tang simultaneously rejected a naïve idealist outlook. Instead, he claimed that it is necessary to brace oneself for the fact that such an ideal world order is unlikely to be ever fully realized over the course of history. He consequently did not aim to issue political prescriptions for state action that will lead to an immediate transformation of political reality. It is indeed this delicate balance between skeptical realism and critical idealism which distinguishes Tang's political writings from mainstream Confucian speculation about modern world order.

78 Ibid., p. 410. 